\title{
Het medisch onderwijs en het NVMO-congres. Waar staan we en hoe moet het verder?
}

\author{
A.J.J.A. Scherpbier
}

\section{Samenvatting}

Veel is veranderd in het medisch onderwijs in Nederland. Alle curricula hebben herzieningen doorgemaakt. Belangrijk hierbij waren de raamplannen artsopleiding en de visitaties met aanbevelingen tot verbetering van de kwaliteit van toetsing, stimulering van onderwijs in kleine groepen en verbetering van het onderwijs in de co-assistentschappen. Thema's die ons nu nog bezighouden. Ook de Nederlandse Vereniging voor Medisch Onderwijs (NVMO) heeft een ontwikkeling doorgemaakt. Het is lastig om een goed beeld te krijgen van de resultaten van alle veranderingen. Het congres en het tijdschrift van de NVMO zijn plekken om hierover te communiceren. Het congres is boeiend en groots. Van 2000-2003 werden 438 abstracts geaccepteerd van 306 eerste auteurs. De kwaliteit van de presentaties wisselt en soms lijkt het of men de literatuur niet goed bijhoudt. Verheugend is dat Nederland in de top 5 staat wat betreft artikelen in Academic Medicine en Medical Education. Helaas publiceren de presentatoren op het NVMO-congres weinig. Dat is jammer, omdat je op een groot congres maar een klein publiek bereikt. Bovendien leidt schrijven tot kwaliteitsverbetering van presentaties. Wellicht kan de NVMO begeleiding bieden om onderzoek van en publiceren over medisch onderwijs te bevorderen. Onderwerpen voor onderzoek en discussie zijn er genoeg. De uitdaging om de onderwijskwaliteit te handhaven bij stijgende studentenaantallen, patiëntgebonden onderwijs, de specialistenopleidingen en de beroepenstructuur vragen onze aandacht. Op het NVMO-congres dit jaar zijn er dan ook workshops voor specialistenopleiders. Alle veranderingen maken professionalisering van het medisch onderwijs nog belangrijker. Hierbij hoort dat we onderzoek doen en daarover presenteren en meer publiceren. (Scherpbier AJJA. Het medisch onderwijs en het NVMO-congres. Waar staan we en hoe moet het verder? Tijdschrift voor Medisch Onderwijs 2004;23(4): 172-177.)

\section{Inleiding}

Er is de afgelopen jaren heel veel gebeurd in het medisch onderwijs. Toen bijvoorbeeld in 1974 in Maastricht gekozen werd voor probleemgeoriënteerd onderwijs, reageerden de andere faculteiten op zijn zachtst gezegd 'meewarig'. "Artsen die zo werden opgeleid, dat kon toch niets worden." Nu hebben alle faculteiten één of meer curriculumherzieningen achter de rug, waarbij ze allemaal de verschuiving van docent- naar studentgecentreerd onderwijs hebben gemaakt. Vele ontwikkelingen hebben daarbij een rol gespeeld.
Genoemd moeten worden de raamplannen artsopleiding en de visitaties. ${ }^{1-4}$ Ook de Nederlandse Vereniging voor Medisch Onderwijs (NVMO) heeft een sterke ontwikkeling doorgemaakt. Wie nu het NVMO-congres bezoekt, kan zich niet meer voorstellen hoe er in het NVMO-bestuur aan het eind van de jaren tachtig werd gewikt en gewogen of er wel of niet een tweedaags congres moest komen. In 1990 was er een experimenteel tweedaags congres en in 1991 werd het eerste Gezond Onderwijs Congres (nu NVMOcongres genoemd) georganiseerd. Wie nu 
het Tijdschrift voor Medisch Onderwijs (TMO) leest, kan zich niet meer voorstellen hoe het Bulletin Medisch Onderwijs er in het begin uitzag. Kortom, er is heel veel gebeurd in medisch-onderwijs-Nederland.

Dit artikel is een reflectie op het medisch onderwijs naar aanleiding van het NVMO-congres 2003, en het kijkt vooruit naar de toekomst van dit onderwijs.

\section{De veranderingen in het medisch onderwijs}

Om een curriculum te kunnen ontwikkelen, moet men weten wat de eindtermen zijn. Dat betekent dat het eindproduct bekend moet zijn. Tot begin jaren zeventig was dat de huisarts. Daarna werd de basisarts het einddoel, maar dat was wel een erg vaag begrip. Het 'Raamplan 1994 artsopleiding' heeft ervoor gezorgd dat de eindtermen voor de opleiding tot basisarts zijn vastgelegd. ${ }^{1}$ In 2001 is het Raamplan verbeterd en zijn de disciplinegebonden eindtermen een bijlage geworden. ${ }^{2}$ De twee visitaties in 1991 en 1996 hebben geleid tot heldere aanbevelingen aan de verschillende faculteiten. ${ }^{3-4}$ Belangrijke thema's zijn onder andere geweest: verbetering van de kwaliteit van toetsing, stimulering van onderwijs in kleine groepen en verbetering van het onderwijs in de co-assistentschappen. Dit zijn thema's die ons nog steeds bezighouden en die in de derde visitatie ook wel weer aan de orde zullen komen.

In de visitatierapporten is ook veel te lezen over verbetering van de curricula. De vele curriculumherzieningen in Nederland zijn gestimuleerd door de visitaties. De visitaties leiden niet tot kwantitatieve resultaten. Dat maakt het lastig om een helder beeld te krijgen van wat de verbeteringen in het onderwijs van de laatste jaren opgeleverd hebben. Kwantitatieve informatie wordt wel vermeld in de Elsevier-enquête, ${ }^{5-12}$ maar het is de vraag hoe betrouwbaar deze is. ${ }^{13}$ Als alleen gekeken wordt naar het verloop van de eindcijfers van de verschillende medische faculteiten tussen 1994 en 2003, dan valt op dat de cijfers niet alleen stijgen, maar ook steeds dichter bij elkaar komen (figuur 1). Dat beeld komt goed overeen met de teksten van de visitaties en de gerealiseerde curriculumherzieningen.

\section{NVMO-congres 2003}

Het NVMO-congres was weer groots en heel goed georganiseerd. De organisatie en de deelnemers krijgen het nu al vele jaren voor elkaar om een boeiend en informatief programma aan te bieden. Tabel 1 laat zien dat er in 2003 meer presentaties waren dan in 2002, waarbij er een opvallende toename is van het aantal posters. Dat zal ongetwijfeld te maken hebben met een iets strenger aannamebeleid voor de papers. Wat betreft de inhoud was er opvallend weinig aandacht voor toetsing en docenten. Opvallend, omdat dit toch wel belangrijke onderwerpen zijn. Er was veel informatie over curricula. De kwaliteit van het gebodene is nog steeds wisselend. Soms viel de diepgang tegen. Het lijkt er ook wel vaker op dat de presentatoren de bestaande literatuur niet zo goed kennen, maar dat is alleen maar een indruk. Ondanks deze kritiek blijft het congres indrukwekkend. Als je de abstractboeken van de afgelopen jaren bekijkt, is de breedte van de onderwijsontwikkeling en van het onderzoek van onderwijs imposant. Zo werden er in de periode 20002003 in totaal 438 abstracts geaccepteerd met 306 verschillende eerste auteurs. 


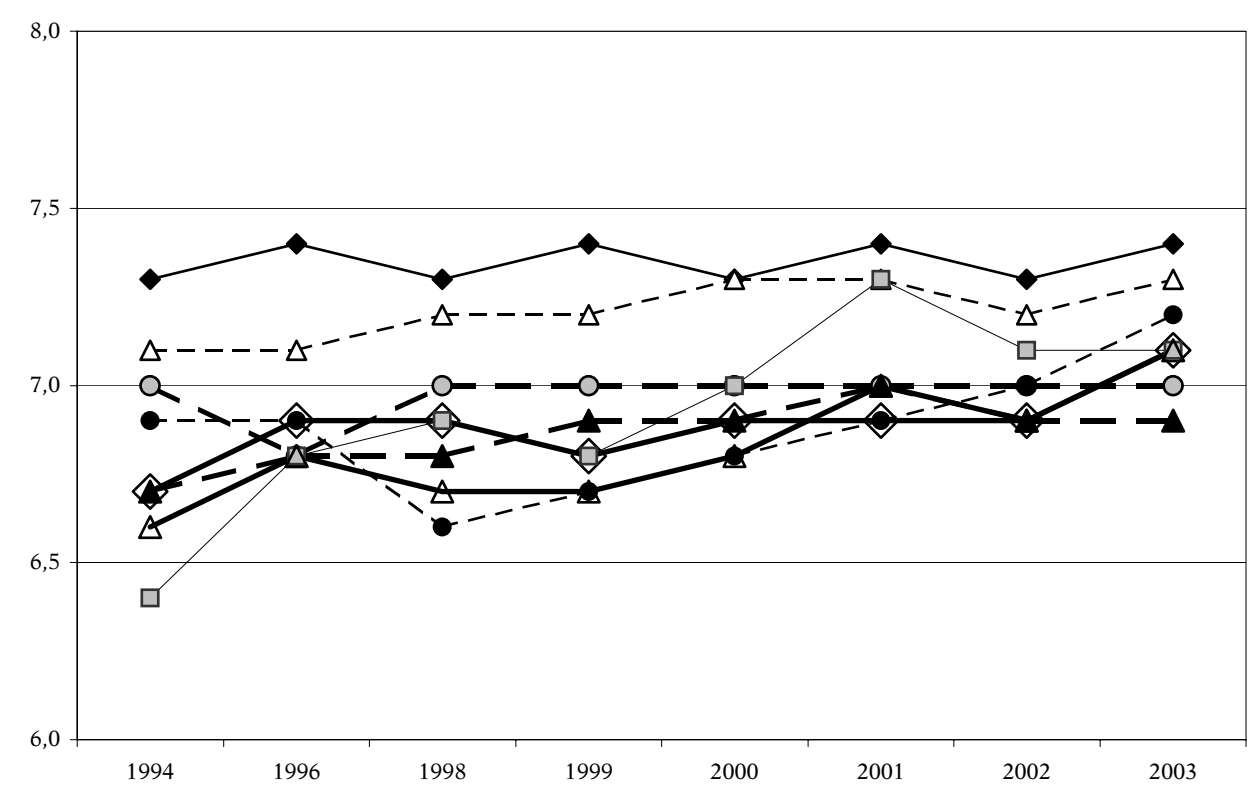

Figuur 1. Eindcijfers van de geneeskundeopleidingen in de Elsevier-enquêtes 1994-2003.

Tabel 1. Verschillende presentatievormen op het NVMO-congres in 2002 en 2003.

\begin{tabular}{lrr}
\hline & $\mathbf{2 0 0 2}$ & $\mathbf{2 0 0 3}$ \\
\hline Papers & 65 & 53 \\
ICT & - & 9 \\
Posters & 18 & 31 \\
$2-2-8$ & 14 & 10 \\
Ronde tafel & 8 & 10 \\
Workshops & 5 & 7 \\
\hline Totaal & $\mathbf{1 1 0}$ & $\mathbf{1 2 0}$ \\
\hline
\end{tabular}

Wat mij echter al jaren opvalt, is dat weinig van de congrespresentaties als publicatie in het TMO verschijnen. De afgelopen jaren wordt slechts ongeveer $10 \%$ van de abstracts in dit tijdschrift gepubliceerd. Dat is om meerdere redenen jammer. De omvang van het congres en de vele parallelle sessies betekenen dat de congresdeelnemers maar een klein deel van de sessies kunnen bijwonen. De informatie in een presentatie bereikt dus maar een kleine groep, waarbij het ook nog maar de vraag is wat de toehoorders ervan onthouden. Dat is jammer van alle energie die de auteurs eraan hebben besteed. Sterker nog, persoonlijk vind ik dat wie niet gaat publiceren, ook niet moet presenteren. Maar dat is misschien wel heel streng.

Er is nog een reden waarom ik het niet goed vind dat er weinig wordt gepubliceerd van wat er wordt gepresenteerd. Als je iets moet opschrijven, dan moet je je in de literatuur verdiepen. Je onderzoeksvraag moet ingebed worden in de bestaande literatuur en je conclusies moeten getoetst worden aan wat we al weten. De kwaliteit van wat je te melden hebt, verbetert daardoor. In een aantal gevallen zal bijvoorbeeld na een goed literatuuronderzoek besloten kunnen worden dat het onderzoek niet nodig is. Als meer presentatoren hun boodschap ook in artikelvorm aanbieden, leidt dat dus uiteindelijk tot een kwaliteits- 
verbetering van de presentaties op het congres. Nu weet ik ook wel dat schrijven niet gemakkelijk is. Maar het is wel te leren.

Kortom, we moeten nadenken over manieren om presentatoren zo ver te krijgen dat ze gaan schrijven en publiceren. We zouden kunnen beginnen met een strengere selectie van de onderzoekspapers en de communicatie over onderwijsontwikkelingen via de andere categorieën, zoals posters en 2-2-8-sessies, stimuleren. Misschien moet er ook wel meer begeleiding geboden worden aan beginnende auteurs of moeten we meer aandacht aan goed onderzoek van onderwijs besteden. Dit lijkt mij een mooie uitdaging voor de deelnemers, de congresorganisatie en de NVMO.

\section{Internationale publicaties van Nederlandse auteurs}

De constatering dat er weinig gepubliceerd wordt in het TMO naar aanleiding van de abstracts op het congres roept de vraag op of publicaties misschien direct naar een internationaal tijdschrift worden gestuurd en hoe vaak Nederlandse auteurs in vergelijking met auteurs uit andere landen internationaal publiceren. In 2002 schreef Tutarel een artikel over de geografische spreiding van publicaties in het medisch onderwijs. ${ }^{14} \mathrm{Hij}$ analyseerde de artikelen die van 1995-2000 in Medical Education en Academic Medicine waren verschenen. Deze Britse en Amerikaanse tijdschriften hebben van de medisch-onderwijstijdschriften de hoogste impactfactor. Tutarel zocht in Medline en registreerde de herkomst van de eerste auteur van alle artikelen in beide tijdschriften. In Academic Medicine werden 2207 artikelen gepubliceerd. De meerderheid kwam uit de Verenigde Staten, namelijk 87.5\% (1931 artikelen). Nederland stond op de derde plaats met 13 artikelen $(0.6 \%)$ (tabel 2).
Tabel 2. Aantal artikelen per land van herkomst in Academic Medicine 1995-2000.

\begin{tabular}{lrr}
\hline & $\begin{array}{r}\text { Aantal } \\
\text { artikelen }\end{array}$ & $\%$ \\
\hline Verenigde Staten & 1931 & $87.50 \%$ \\
Canada & 160 & $7.25 \%$ \\
Nederland & 13 & $0.60 \%$ \\
Israel/Zwitserland/ & & \\
Verenigd Koninkrijk & 10 & $0.45 \%$ \\
\hline
\end{tabular}

In Medical Education werden 746 artikelen gepubliceerd. De eerste plaats was voor het Verenigd Koninkrijk met 318 artikelen $(42.6 \%)$ en Nederland kwam op de vijfde plaats met 26 artikelen (3.5\%) (tabel 3). Om na te gaan of de relatieve positie van Nederland veranderd is, werd gekeken naar de herkomst van de eerste auteur van artikelen in Medical Education in 2002 en 2003. Het blijkt dat de relatieve positie van Nederland versterkt is. We stonden op de vijfde plaats met 3.5\% en we staan inmiddels op de vierde plaats met $7.2 \%$ van de artikelen (tabel 3 ). Het ging in 2002 en 2003 om 19 artikelen en in 1995-2000 om 26 artikelen. Ook in absolute zin is er dus een stijging, namelijk van 5 artikelen per jaar naar 9 artikelen. In vergelijking met de andere landen in de top 5 zijn we een klein land. Wat dat betreft is het een hele prestatie. Het is ook een hele prestatie, omdat het in de afgelopen periode moeilijker is geworden om een artikel in Medical Education geplaatst te krijgen. Uit de aantallen internationale artikelen blijkt al dat er niet veel vanuit het congres internationaal wordt gepubliceerd. Van de eerste auteurs die internationaal publiceren komt zelfs bijna de helft niet voor als eerste auteur in de lijst van abstracts. Het is de vraag waar dat aan ligt. Begeleiden zij alleen en staan zij dus als laatste auteur genoemd? Is het congres voor hen geen aantrekkelijk 
forum? Heeft het iets te maken met de kwaliteit? Ik heb het antwoord (nog) niet.

Tabel 3. Percentage artikelen uit verschillende landen in Medical Education.

\begin{tabular}{lrr}
\hline & $\mathbf{1 9 9 5}^{-2000}$ & \\
\hline Verenigd Koninkrijk & $\mathbf{2 0 0 2 - 2 0 0 3}$ \\
Australië & $11.7 \%$ & $44.8 \%$ \\
Verenigde Staten & $10.5 \%$ & $8.4 \%$ \\
Canada & $5.8 \%$ & $15.2 \%$ \\
Nederland & $3.5 \%$ & $6.4 \%$ \\
Overig & $25.9 \%$ & $7.2 \%$ \\
\hline
\end{tabular}

\section{Wat gaat er in de toekomst gebeuren?}

Op een aantal faculteiten wordt gewerkt aan curriculumherzieningen. Het is spannend om te zien of we er in zullen slagen de onderwijskwaliteit die de afgelopen jaren is bereikt te handhaven bij de grotere aantallen studenten. Voor het met elkaar communiceren over dit probleem en het gezamenlijk zoeken naar oplossingen is het congres een goed forum.

Verbeteringen in het patiëntgebonden onderwijs worden gefaciliteerd door hogere affiliatietarieven en nieuwe affiliatiecontracten. In de contracten worden ook eisen gesteld aan de scholing van docenten. Dit is een uitdaging voor de NVMO. In de vervolgopleidingen zijn ook grote aanpassingen te verwachten. Enerzijds moeten er in een aantal opleidingen grotere aantallen worden opgeleid. Anderzijds is besloten tot modernisering van de opleidingsmethoden. ${ }^{15}$ Dit betekent dat er vanuit specialistenopleiders een behoefte ontstaat om meer te weten over onderwijsontwikkeling. De organisatoren van het NVMO-congres 2004 hebben hier al op ingespeeld door een aantal workshops voor specialistenopleiders aan te bieden. Om voldoende capaciteit te houden om goede zorg te kunnen blijven verlenen, worden ook nieuwe beroepen geïntrodu- ceerd, zoals de nurse practitioner en de physician assistant. Dit moet leiden tot een nieuwe beroepenstructuur. 15-16

De veranderingen in de basisartsopleiding en in de vervolgopleiding, zoals geschetst in de rapporten 'De arts van straks' en 'De zorg van morgen', betekenen ook dat er ontwikkeld kan worden aan het opleidingscontinuüm. ${ }^{17-18}$ De komende jaren zal er dus veel blijven veranderen en dat biedt voor de NVMO veel mogelijkheden en uitdagingen. Bij de verdere professionalisering hoort dat we aan de kwaliteit van het congres moeten blijven werken en dat we meer onderzoek doen naar alle ingevoerde onderwijsveranderingen. Vervolgens is het belangrijk dat we daarover presenteren en er meer over publiceren.

\section{Literatuur}

1. Metz JCM, Pels Rijcken-van Erp Taalman Kip EH, Brand van den-Valkenburg BWM. Raamplan 1994 artsopleiding: eindtermen van de artsopleiding. Nijmegen: Universitair Publikatiebureau Katholieke Universiteit Nijmegen; 1994.

2. Metz JCM, Verbeek-Weel AMM, Huisjes HJ, editors. Raamplan 2001 artsopleiding: bijgestelde eindtermen van de artsopleiding. Nijmegen: Mediagroep; 2001.

3. VSNU. Visitatierapport geneeskunde en gezondheidswetenschappen. Utrecht: VSNU; 1992.

4. VSNU. Onderwijsvisitatie geneeskunde en gezondheidswetenschappen. Utrecht: VSNU; 1997.

5. Elsevier/ NIPO's universiteitentest. Elsevier 25 oktober 1994;50:28-54.

6. Elsevier/ NIPO's onderzoek 1996; universiteitentest. Elsevier 19 oktober 1996;52:32-49.

7. Elsevier special. Universiteitentest. Elsevier/NIPO's onderzoek 1998. Bijlage bij Elsevier nr. 39;26 september 1998.

8. Elsevier special. De beste studies. Speciale uitgave van Elsevier, oktober 1999:38-40.

9. Elsevier special. De beste studies. Speciale uitgave van Elsevier, oktober 2000.

10. De beste hogescholen en universiteiten; onderzoeken NIPO en IOWO 2001. Speciale uitgave van Elsevier, oktober 2001.

11. Gezondheidszorg. In: Studeren: welke hogeschool of universiteit? Thema, speciale uitgave van Elsevier, oktober 2002:82-4.

12. WO: gezondheid. In: Elsevier thema, studeren, oktober 2003:40-4. 
13. Scherpbier AJJA, Zwierstra RP. De kwaliteit van de medische opleidingen getoetst? Tijdschrift voor Medisch Onderwijs 2002;21(1):2-8.

14. Tutarel O. Geographical distribution of publications in the field of medical education. BMC Med Educ 2002;2:3. http://www.biomedcentral.com/1472-6920/2/3.

15. Schilfgaarde R van. Naar een nieuwe beroepenstructuur. Functionele overwegingen bij de capaciteitsproblematiek. ZM magazine 2004;1:9-12.

16. Meyboom-De Jong B, Schmit Jongbloed LJ. De arts van de toekomst: de aanbevelingen van 'De arts van straks' nader toegelicht. Tijdschrift voor Medisch Onderwijs 2003;22(5):222-8.

17. Meyboom-de Jong B, Schmit Jongbloed LJ, Willemsen MC, editors. De arts van straks. Een nieuw medisch opleidingscontinuüm. Utrecht: KNMG; 2002. www.deartsvanstraks.nl.

18. De zorg van morgen. Flexibiliteit \& samenhang. Advies van de Commissie Implementatie Opleidingscontinuüm en Taakherschikking. Den Haag; 10 juli 2003.

\section{De auteur:}

Prof. dr. A.J.J.A. Scherpbier is hoogleraar en wetenschappelijk directeur van het Onderwijsinstituut van de Faculteit der Geneeskunde, Universiteit Maastricht. Tevens is hij voorzitter van de NVMO.

Correspondentieadres:

Prof. dr. A.J.J.A. Scherpbier, Universiteit Maastricht-FdG, Onderwijsinstituut Geneeskunde, Bureau Onderwijs, Postbus 616, 6200 MD Maastricht, tel: 043-3881400, fax: 043-3884165,a.scherpbier@oifdg.unimaas.nl.

\section{Summary}

All Dutch undergraduate medical curricula have recently undergone extensive renovations. Important catalysts for change were the educational audits and "Blueprint 1994" and "Blueprint 2001". They strongly advocated improved quality of assessment, improved clerkship training and small-group teaching. Themes that continue to engage our attention. The Dutch Association for Medical Education (NVMO) has also changed. It is easy to lose sight of the overall picture amidst the plethora of innovations. Fortunately, NVMO conferences and the Dutch Journal of Medical Education offer platforms to exchange ideas and keep up with key trends. The conference is interesting and grand. Between 2000-2003, 438 abstracts from 306 different first authors were accepted. Presentations vary in quality and occasionally one wonders whether authors have read the literature. It is encouraging that the Netherlands is among the five countries with the most articles published in Academic Medicine and Medical Education. However, the reluctance of presenters at the NVMO conference to publish is disappointing. The more so since presentations, even at a huge conference, reach only a small audience. Publishing improves the quality of presentations. The NVMO would do well to encourage aspiring authors. Subjects are plentiful: the challenge to maintain educational quality with rapidly rising student numbers, the role of patients in education, specialty training, and the changes in the health care professions. The next conference will feature workshops on specialty training. In a dynamic field, professionalisation of the players should stay high on the agenda. Research and publication of the results are essential components of professionalisation. (Scherpbier AJJA. Medical education and the congress of the Dutch Association for Medical Education (NVMO). Where do we stand and how should we go on? Dutch Journal of Medical Education 2004;23(4): 172-177.) 